\title{
Optimization and Innovation of Screw Joints of Micron-Wood-Fiber Molded Products
}

\author{
Chengyi Pan and Jianyi Zhang \\ School of Mechanical and Power Engineering, Harbin University of Science and \\ Technology, 150080, Harbin, P.R. China \\ \{Chengyi.Pan, Jianyi.Zhang, pcy8706\} @yahoo.com.cn
}

\begin{abstract}
Micron-wood-fiber molded products are new kinds of high strength man-made wooden products. They are innovative products among molded fiber products nowadays. This paper studied a new method to design their screw joints using optimal design. It has combined the optimal design with reliability design ingeniously. The CAD programming method was put forward, which can optimize the structural parameters of micron-wood-fiber molded products, and may be used on the strength design and the check of innovation for new products. The new calculating method and software had provided effective design method for screw joints of micron-wood-fiber molded products. It would increase the calculating efficiency and precision greatly.
\end{abstract}

Keywords: Micron-wood-fiber molded products, screw joints, optimal design, CAD, innovation.

\section{Introduction}

Micron-wood-fiber molded products are new kinds of high strength man-made wooden products [1]. They are innovative products among molded fiber products nowadays. They can be used as inner decorates of luxurious cars or crooked part of furniture. Such as panel, handle, doorknob, steering wheel, handrail of sofa, joint elbow and so on [2]. These parts have complex and curve forms, so the conventional manufacturing process is troublesome. The innovation of micron-wood-fiber molded products will solve the problem, and also the problems of material shortage, molding technology and high cost. In addition, screw joints are used in these products often. Because the stress and strength of the screw threads of micron-wood-fiber molded products have certain distributing state and great variability, it's obviously rough to calculate using conventional design method. Although using reliability design is close to engineering practice, but the optimum structural parameters can't be obtained. For this reason, this paper proposed optimal design with reliability for the strength of screw joints of these innovative products. Taking advantage of CAD software, the strength reliability target is fulfilled and the optimum structural parameters can be obtained. The method would increase the calculating efficiency and precision greatly. 


\section{Mathematic Model Establishment}

\subsection{Objective Function Establishment}

As shown in Fig.1, a micron-wood-fiber molded product is fixed to a plate part by a group of screw. In working, load $F$ acts on the micron-wood-fiber molded product. The largest diameter of screw is $D$; the number of screws is $m$; the number of threads of the screws is same, and is to be $z$. The diameter of the circle on which the centers of the screw are arranged is $\phi$. The screws are distributed uniformly along the circle. Omitting those random factors of manufacturing, assembly and materials, the instances of every screw joint are same. The stress and strength of the screw joints are both in accordance with normal distribution. In order to find the optimal solution of structural parameters, optimal design with reliability would be used. Obviously, the cost of the jointed parts is relative to the structural parameters. In order to make the cost to be the least, we take design variables as:

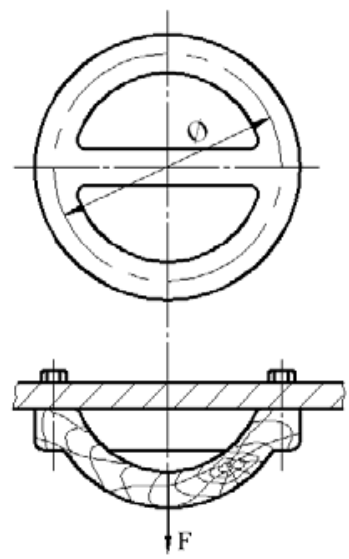

Fig. 1. Screw joints of micron-wood-fiber molded product

$$
\boldsymbol{X}=\left[x_{1}, x_{2}, x_{3}, x_{4}\right]^{\mathrm{T}}=[m, D, z, \phi]^{\mathrm{T}}
$$

The objective function is established as following:

$$
\min F(\boldsymbol{X})=m D z \phi=x_{1} x_{2} x_{3} x_{4}
$$

\subsection{Restrictive Condition Establishment}

\subsubsection{Restrictive Condition of Strength Reliability}

From experiments, the main failure is the bending crack of threads of micron-woodfiber molded products. The load of every screw is $F / m$. The mathematical expectation of bending stress of screw thread [3] of micron-wood-fiber molded product is 


$$
\mu_{1}=\frac{3 F h}{\pi D t_{1}^{2} z m}
$$

Where $\mathrm{h}$ - height of screw thread of micron-wood-fiber molded product, $\mathrm{h}=0.54 \mathrm{P}$, $\mathrm{P}$ is the pitch [4];

$-\mathrm{t}_{1}$-width of root of screw thread of micron-wood-fiber molded product, $\mathrm{t}_{1}=0.75 \mathrm{P}[4]$.

The relation of $P$ and $D$ can be calculated as

$$
P=0.0078125 D^{2}-0.15625 D+2.5
$$

In order to calculate the reliability of strength of screw thread of micron-woodfiber molded product, the reliability coefficient $Z_{\mathrm{R}}$ must be calculated first [5].

$$
Z_{\mathrm{R}}=\frac{\mu_{\mathrm{s}}-n \mu_{1}}{\sqrt{\sigma_{\mathrm{s}}^{2}+\sigma_{1}^{2}}}
$$

Where $\mu_{\mathrm{s}}$ mathematical expectation of load capacity of screw thread of micronwood-fiber molded product, Mpa;

- $\sigma_{\mathrm{s}}$-mean square deviation of load capacity of screw thread of micron-woodfiber molded product, $\mathrm{MPa}$;

- $\sigma_{1} \_$mean square deviation of bending stress of screw thread of micron-woodfiber molded product, $\mathrm{MPa}$;

- $n$ - reserve coefficient of strength, $n=1.1 \sim 1.25$.

$\sigma_{\mathrm{s}}=C_{\mathrm{k}} \mu_{\mathrm{s}} ; \sigma_{\mathrm{l}}=S_{\mathrm{k}} \mu_{1} . C_{\mathrm{k}}$ and $S_{\mathrm{k}}$ are variable coefficients of material and stress respectively. We take $C_{\mathrm{k}}=0.14, S_{\mathrm{k}}=0.08$ [5].

Eq. (5) is the connection equation. Using this equation and taking reliability as restrictive condition, it can be connected with optimal design. That is reliability optimal design. Take Eq.(3) to Eq.(5), we obtain

$$
Z_{\mathrm{R}}=\frac{\mu_{\mathrm{s}}-n \frac{3 F h}{\pi D t_{1}^{2} z m}}{\sqrt{\left(C_{\mathrm{k}} \mu_{\mathrm{s}}\right)^{2}+\left(S_{\mathrm{k}} \frac{3 F h}{\pi D t_{1}^{2} z m}\right)^{2}}}
$$

The strength reliability can be calculated from the following equation:

$$
R=\frac{1}{\sqrt{2 \pi}} \int_{-Z_{\mathrm{R}}}^{\infty} e^{-\frac{t^{2}}{2}} d t
$$


Taking Eq.(6) to Eq.(7), we obtain

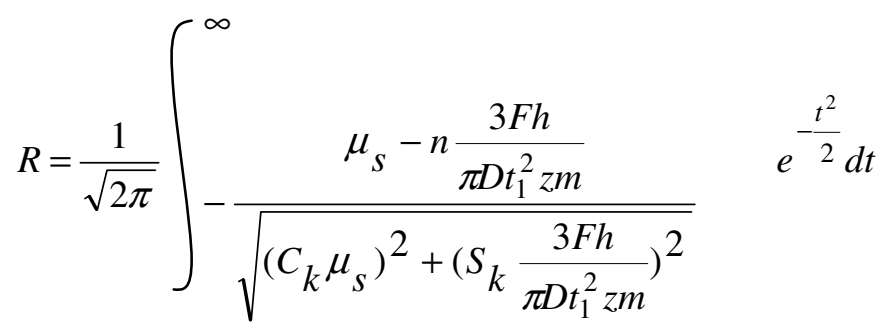

If the allowable reliability is $[R]$, the restrictive condition of strength reliability should be

$$
g_{1}(x)=\frac{1}{\sqrt{2 \pi}} \int_{-\frac{\mu_{\mathrm{s}}-n \frac{3 F h}{\pi x_{2} t_{1}^{2} x_{3} x_{1}}}{\sqrt{\left(C_{k} \mu_{\mathrm{S}}\right)^{2}+\left(S_{k} \frac{3 F h}{\pi x_{2} t_{1}^{2} x_{3} x_{1}}\right)^{2}}}}
$$

\subsubsection{Restrictive Conditions of Structural Parameters}

In order to insure the enough working room for wrench, the peripheral distances of the screws should not be less than $5.5 D$. So the restrictive condition of wrench room is

$$
\frac{\pi \phi}{m}-5.5 D \geq 0
$$

That is

$$
g_{2}(x)=\frac{\pi x_{4}}{x_{1}}-5.5 x_{2} \geq 0
$$

In order to insure the intension between the jointed parts, the peripheral distances of the screws should not be large than $11 D$. So the restrictive condition of intension is

$$
11 D-\frac{\pi \phi}{m} \geq 0
$$

That is

$$
g_{3}(x)=11 x_{2}-\frac{\pi x_{4}}{x_{1}} \geq 0
$$


The structural parameters are also defined by experience and requirements:

$$
\begin{gathered}
m_{\min } \leq m \leq m_{\max } \\
D_{\min } \leq D \leq D_{\max } \\
z_{\min } \leq z \leq z_{\max } \\
\phi_{\min } \leq \phi \leq \phi_{\max }
\end{gathered}
$$

Consequently, the other restrictive conditions of structural parameters are

$$
\begin{aligned}
& g_{4}(x)=x_{1}-m_{\text {min }} \geq 0 \\
& g_{5}(x)=m_{\text {max }}-x_{1} \geq 0 \\
& g_{6}(x)=x_{2}-D_{\text {min }} \geq 0 \\
& g_{7}(x)=D_{\text {max }}-x_{2} \geq 0 \\
& g_{8}(x)=x_{3}-z_{\text {min }} \geq 0 \\
& g_{9}(x)=z_{\text {max }}-x_{3} \geq 0 \\
& g_{10}(x)=x_{4}-\phi_{\text {min }} \geq 0 \\
& g_{11}(x)=\phi_{\text {max }}-x_{4} \geq 0
\end{aligned}
$$

\section{Programming for Optimal Design}

Above calculation is difficult unless taking advantage of computer. So a software or program is necessary. The programming employed the seeking method of stochastic directions. The step is $A=1$; the convergence precision is $E=1$; the max allowable number of direction seeked on computing point is $N=50$, the convergence precision of objective function is $E_{1}=1$. The flow chart of parameter computing is shown in Fig.2.

For example, the load is $F=1000 \mathrm{~N}$. The bending strength of micron-wood-fiber molded product is $\mu_{\mathrm{s}}=39 \mathrm{Mpa}$ [6]. The diameter of the circle on which the screw are distributed is $\phi=100 \mathrm{~mm} \sim 160 \mathrm{~mm}$. The number of thread of a screw is $z=5 \sim 10$. The largest diameter of screw is $D=10 \mathrm{~mm} \sim 20 \mathrm{~mm}$. The number of screw is $\mathrm{m}=2 \sim 12$. The strength reliability of thread is not less than $95 \%[7,8]$. The optimal result computed by the software is 


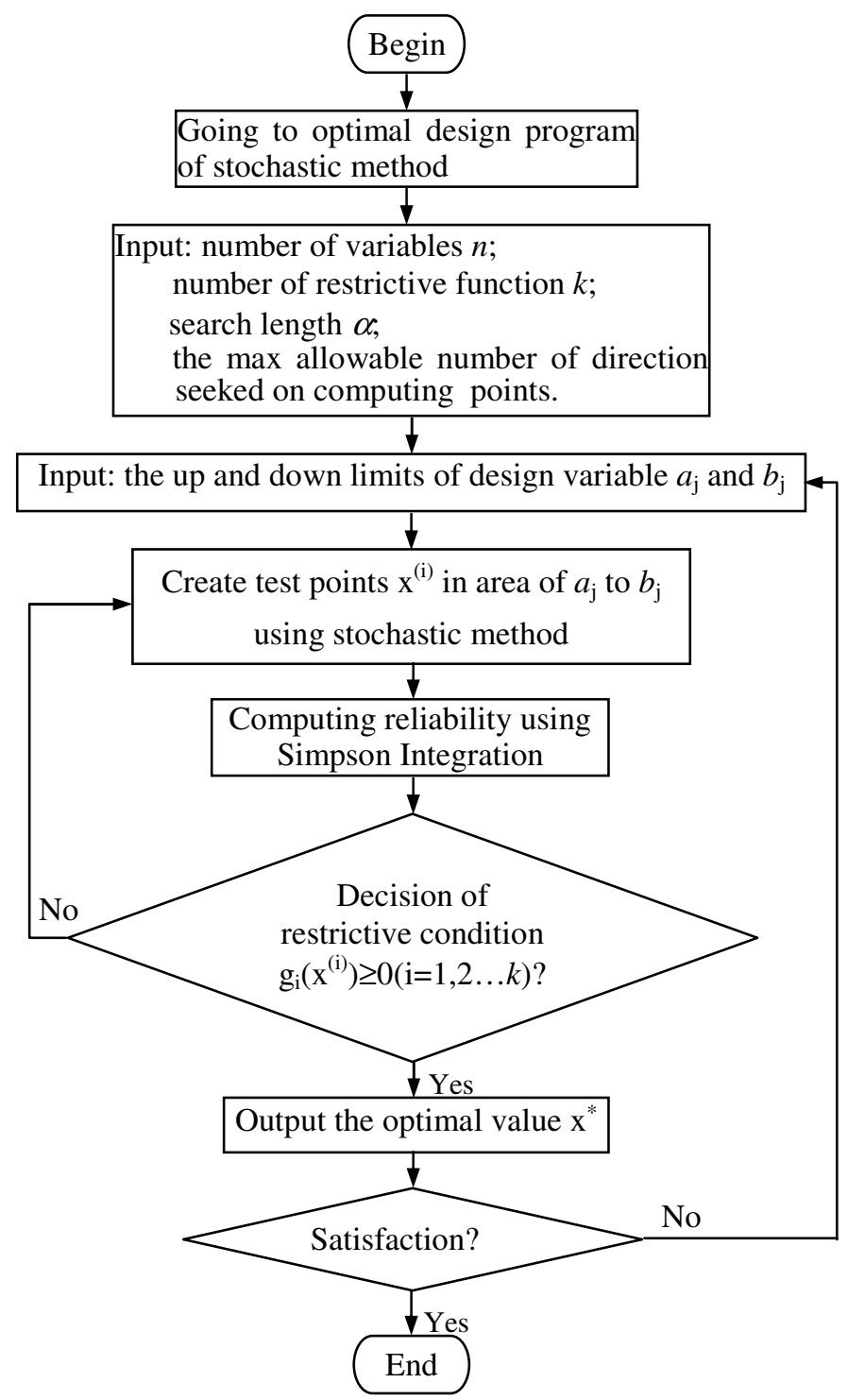

Fig. 2. Flow chart of parameter computing

$$
X^{*}=\left[\begin{array}{l}
x_{1} \\
x_{2} \\
x_{3} \\
x_{4}
\end{array}\right]=\left[\begin{array}{l}
m \\
D \\
z \\
\phi
\end{array}\right]=\left[\begin{array}{c}
4 \\
12 \\
5 \\
150
\end{array}\right]
$$




\section{Conclusions}

This paper has put forward the optimal design with reliability for screw joints of micron-wood-fiber molded products. This new method uses reliability design and optimal design comprehensively. Using computer and software, the strength reliability is fulfilled and the optimum structural parameters are obtained. The method is advanced and has great practical value. It is an innovative method for innovative products. Micronwood-fiber molded products have good prospect and would be widely applied. So the new design method for the new product will bring economic and social benefits.

\section{Acknowledgments}

The authors would like to acknowledge the support of Education Department Project of Science and Technology of Heilongjiang Province (11531041).

\section{References}

1. Ma, Y., Pan, C.: Experimental Equipment and Technology of Forming Micron Wood Fiber mould Product. J. Scientia Silvae Sinicae 44(6), 113-117 (2008)

2. Pan, C., Yang, C.: Industrial Prospects and Beneficial Prediction of Micron Wood-fiber Mould-product of Our Country. J. Forestry Machinery \& Woodworking Equipment 35(11), 18-20 (2007)

3. Qiu, X.: Machine Design. Higher Education Press, Beijing (2000)

4. Editorial Board of Handbook of Mechanical Design: Handbook of Mechanical Design. China Machine Press, Beijing (2004)

5. Chen, J.: Mechanical Reliability Design. China Machine Press, Beijing (1988)

6. Ma, Y.: Study on Composition of Micron Flake Fiber High Strength Board. J. China Forest Products Industry 32(4), 6-8 (2005)

7. Pan, C., Ma, Y.: The Theoretical Research on Calculation of Nail Holding Power of Micron Wood Fiber Product by Mould Pressing. J. Scientia Silvae Sinicae 43(9), 63-67 (2007)

8. Pan, C., Ma, Y.: Calculation of Load Distribution Coefficient at the Binding Site of the Holding Nail of Micron Wood-fiber Molded Products. J. Mechanical Science and Technology for Aerospace Engineering 26(8), 977-981 (2007) 